Sādhanā Vol. 40, Part 2, April 2015, pp. 605-622. (c) Indian Academy of Sciences

\title{
Thermal front propagation in variable aperture fracture-matrix system: A numerical study
}

\author{
NIKHIL BAGALKOT* and G SURESH KUMAR \\ Department of Ocean Engineering, Indian Institute of Technology Madras, \\ Chennai 600 036, India \\ e-mail: nikhilbagalkot@gmail.com; gskumar@iitm.ac.in
}

MS received 02 June 2014; revised 03 September 2014; accepted 08 November 2014

\begin{abstract}
A numerical study on the effect of complex fracture aperture geometry on propagation of thermal front in a coupled single fracture-matrix system has been carried out. Sinusoidal and logarithmic functions have been used to capture the variation in fracture aperture. Modifications have been made to existing coupled partial differential governing equations to consider the variation of fracture aperture. Effect of temperature on the thermal and physical properties of rock have been incorporated. A fully implicit finite difference scheme has been used to discretize the coupled governing equations. Thermal convection, dispersion and conduction are the major transport processes within fracture, while conduction is the major transport process within rock matrix. The results suggest that variation of fracture aperture increases the heat transfer rate at the fracture-matrix interface. Sensitivity analysis on rock thermal conductivity and fracture aperture have been carried out. The results suggest that the heat transfer from rock matrix to fracture for the case of the parallel plate model is greatly dependent on the rock thermal conductivity $\left(\lambda_{\mathrm{m}}\right)$ as compared to variable aperture model. Further, the thermal front propagation for both parallel plate model and variable aperture model is sensitive to changes in fracture aperture. The heat transfer rate at the interface is greater at smaller fracture apertures and decreases with increase in aperture.
\end{abstract}

Keywords. Thermal front; variable aperture; rock-matrix; geothermal reservoir; numerical model, liquid dominated.

\section{Introduction}

Rapid commercialization in recent years has created a considerable increase in the demand for energy. This has put excessive strain on the conventional power generation units (thermal, hydro and nuclear). With ever-increasing costs and depletion of conventional energy sources (natural gas, coal, nuclear, etc.), the cost of producing energy from these sources is rapidly rising.

${ }^{*}$ For correspondence 
Another major concern is the negative impact that most of these technologies have on climate and associated life forms. Hence it has become critical to look towards unconventional renewable forms of energy production technologies with minimal effect on environment and to reduce the dependence on existing conventional forms of energy. Geothermal energy from hot rocks has emerged as a promising unconventional renewable energy production technology, the author has previously analysed coupled heat and mass transfer through fractured geothermal reservoirs (Suresh Kumar \& Ghassemi 2005; Natarajan \& Suresh Kumar 2011b).

The heat source in these rocks may be from volcanic activity, high geothermal gradient or the presence of hydrothermal system nearby. The basic method is to drill a well into the region of low permeability hot rock $(<500 \mathrm{~K})$. Cold water is then pumped through the injection well in the region of the hot rock. As cold water circulates through the hot rock region it gets heated up. The hot water is then extracted from the production well which in turn is used to generate usable energy. Hence it becomes very critical to study and understand the nature of heat exchange between the cold water and hot fractured rock to access the feasibility of geothermal energy production.

Propagation of thermal fronts in a single phase fractured porous media was first studied by Lauwerier (1955). Lauwerier developed an analytical solution for injection of hot water into oil bearing fractured rocks. Gringarten \& Sauty (1975) developed a mathematical model for investigating the unsteady temperature behaviour of a pumped aquifer during reinjection of a fluid at a temperature different from that of the native water for a single horizontal fracture. Gringarten et al (1975) extended analytical solution for vertical fractures. Analytical solution from thermal propagation in a single fracture to fracture network, was extended by Heuer et al (1991) and Schulz (1987). Cheng et al (2001) provided an integral equation formulation for multidimensional heat flow in a single fracture. Suresh Kumar \& Ghassemi (2005) analysed non-isothermal quartz dissolution/precipitation in a coupled fracture-matrix system. Natarajan \& Suresh Kumar (2011b) included the fracture skin in the analysis of thermal front propagation in fracture-matrix system. Analysis of flow and heat transport in single and multiple fractures-matrix system in 3D was carried out by Kolditz \& Christoph (1998). Shook (2001) showed that the reinjection of cold water will rapidly advance thermal front propagation through high permeability fractures causing a premature breakthrough at the production well and hence influencing significantly the efficiency of the system.

Most of studies carried out on thermal front propagation in single fracture-matrix system apply the conventional parallel plate model. The parallel plate model assumes fluid flow to be between two smooth parallel plates, which effectively means a constant fracture aperture. This assumption ignores the naturally existing wall roughness and spatial variation of the fracture aperture along fracture, which have a significant effect on the propagation of thermal fronts. Experiments and field studies conducted by Keller \& Bonner (1985) and Hakami \& Barton (1990) to understand the geometry of naturally occurring fractures, observed that fractures tend to have very complex geometry and the aperture width varies along fracture length. This causes the fluid flow path through the fracture to be very tortuous unlike the parallel plate model. A constant velocity of fluid cannot be sustained through this tortuous path as described by the parallel plate model. Instead, the fluid velocity varies along the fracture length due to change in cross-sectional area through which the fluid passes. Witherspoon et al (1980) experimentally proved that the cubic law is valid for flow through fracture. The cubic law provides the flow rate $(q)$ of the highly viscous, non-turbulent fluid through an open fracture as a function of cube of fracture aperture as represented in Eq. (1).

$$
q=\frac{b^{3} \Delta p}{12 \mu L_{f}} .
$$


In Eq. (1), $L_{f, \mu}, b$ and $p$ are length of fracture (m), viscosity of fluid $\left(\mathrm{N} \cdot \mathrm{s} / \mathrm{m}^{2}\right)$, half fracture aperture $(\mathrm{m})$ and pressure $\left(\mathrm{N} / \mathrm{m}^{2}\right)$, respectively. From Eq. (1) it can be seen that the flow rate $(q)$ varies as cube of fracture aperture, hence even a small variation in aperture width will result in significant change of flow rate through fracture. Thermal convection, dispersion and conduction are the mechanisms that have a major influence on the propagation of thermal fronts in a fracture. Convection and dispersion are dependent on velocity of the fluid which in turn is a function of fracture aperture width (Harr 1962; Grisak \& Pickens 1980). Considering the variable aperture can help in proper accounting for advection and dispersion in a fracture and capture the undulating patterns of the fracture wall which dramatically increases reacting surface area. Very few studies have considered variation of fracture aperture in analysing flow and transport in single coupled fracture-matrix system (Zimmerman \& Bodvarsson 1996; Liu 2005; Liu \& Fan 2011). Natarajan \& Suresh Kumar (2010) have studied solute transport in coupled fracture-skin-matrix system in the presence of a sinusoidal fracture aperture. However, these studies were limited to solute transport in fracture-matrix system.

Thermal conduction coefficient of the rock matrix governs the temperature at the interface of the fracture and rock matrix which in turn effects the thermal front propagation in the fracture. The rock thermal diffusivity depends on thermal conductivity of rock, rock density and specific heat of rock, and all these parameters vary as a function of temperature. Hence it is essential to include the variation of these parameters as function of temperature for accurate analysis of the thermal front propagation. However, most of the studies in thermal front propagation consider these parameters constant with respect to temperature (Suresh Kumar \& Ghassemi 2005; Natarajan \& Suresh Kumar 2011a; Cheng et al 2001). A generalized empirical equation for the temperature dependence of thermal conductivity of rock is given by Zoth \& Haenel (1988). Similarly, Somerton (1992) gave generalized empirical equations for temperature dependence of rock density and rock specific heat.

Propagation of thermal front in fracture-matrix system have followed a pattern similar to groundwater (solute transport). Similar phenomena (convection, thermal dispersion and conduction) govern the thermal front propagation as compared to solute transport (advection, dispersion, and diffusion). For the case of solute transport, the nature of injection (boundary conditions) of solute influences the transport of solute both in fracture and rockmatrix (Batu \& Genuchten 1990; Logan et al 1996; Allaire et al 2002). Since the nature of boundary condition or the particle injection has influence on the transport of solute, boundary conditions may also have an influence on propagation of thermal transport in fracture-matrix system. Most of the studies whether solute transport or thermal front propagation have used simple Dirichlet boundary condition (Suresh Kumar \& Ghassemi 2006; Suresh Kumar and Sekhar 2005; Suresh Kumar 2008, 2009, 2014; Natarajan \& Suresh Kumar 2011a; Renu \& Suresh Kumar 2012). To understand whether the nature of boundary conditions of the fluid temperature effects the propagation of thermal front in fracture-matrix system it is important to include different types of inlet boundary condition.

The focus in the present study is to understand the effect of the fracture aperture variation on propagation of thermal fronts in a single coupled fracture-matrix system. It is hard to predict the exact nature of the fracture aperture geometry. However, some experimental studies have revealed that natural porous media exhibit self-similarity up to a certain scale (Feder 1988) and this concept may also be extended to fractured porous media. The self-similarity concept is applied in the present study, two distinct geometrical profiles: sinusoidaly and logarithmically varying aperture have been used to describe (figure 1) the variation of the fracture aperture. Present study also investigates the effect of various types of water injection boundary condition on the thermal front propagation. Apart from conventional Dirichlet type of boundary condition, Neumann boundary condition has also been applied. Further, for Neumann type boundary 


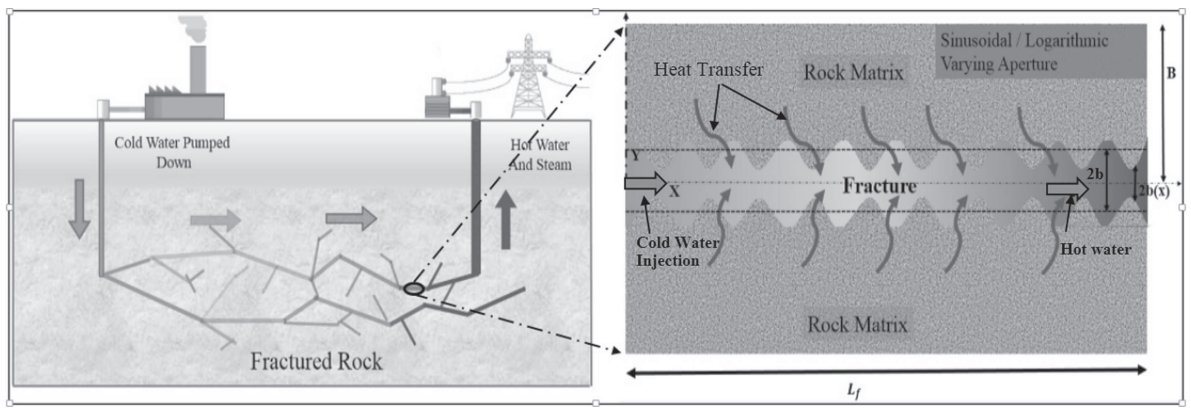

Figure 1. Schematic diagram of the enhanced geothermal systems (EGS), with a single horizontal fracture in granite rock.

condition, two different functions have been used: exponential variation with time and sinusoidal variation with time. Sensitivity analysis on fracture aperture and thermal conductivity of rock matrix has been carried out, as these parameters effectively control the thermal front in fracture.

\section{Physical system and governing equations}

Figure 1 illustrates the geothermal system along with depiction of thermal front propagation in single fracture. Cold water is injected from surface trough the injection well into the region of hot fractured rocks. The injected cold water circulates through hot fractured rock and is extracted at surface through the production well as hot fluid. The hot fluid from the production well may be water or steam or combination of both depending on whether the geothermal system is liquid dominated (water) or vapour dominated (steam/steam and water). Figure 1 also illustrates a single horizontal fracture. The dashed line parallel to axis of fracture represents the equivalent aperture for the parallel plate model. In figure $1,2 b$ is the fracture aperture pertaining to the parallel plate model, $2 b(x)$ represents fracture aperture for the variable fracture aperture model (sinusoidal and logarithmic), $B$ is the half fracture spacing, and $L_{f}$ is the length of the fracture.

Thermal convection, dispersion and conduction are the major transport processes considered within fracture, while conduction is the major transport process within rock matrix. Additionally, heat flux transfer between rock matrix and fracture is also considered.

Following assumptions have been applied in the present study.

(i) Transport in fracture is assumed to be $1 \mathrm{D}$ with fluid flowing horizontally.

(ii) Transport in rock matrix is assumed to be $1 \mathrm{D}$ with the transport of the fluid perpendicular to flow in fracture.

(iii) The fracture aperture is much smaller in comparison with fracture length $\left(b<<<L_{f}\right)$.

(iv) Convection in rock matrix is assumed to be non-existent due to assumption that there is no fluid flow in rock matrix.

(v) Thermal dispersion is analogous to dispersion of solutes in fracture-matrix system.

(vi) There exist a pressure equilibrium between fracture and rock matrix.

(vii) Specific heat capacities are not a function of temperature.

(viii) Symmetry is assumed about the fracture axis. Hence the solution is restricted to one of half of fracture and its adjoining porous rock matrix (Sudicky \& Frind 1982; Natarajan \& Suresh Kumar 2011a). 
(ix) A single phase of fluid exists (water) and there is no change in fluid enthalpy (Cheng et al 2001; Shook 2001; Suresh Kumar \& Ghassemi 2005).

On the basis of above assumptions and transport processes, thermal front propagation in a single coupled fracture-matrix system can be described by two coupled partial differential equations. One equation representing the thermal transport in fracture and the other representing thermal transport in rock matrix. These two equations are coupled and coupling is provided by the continuity of fluxes between them along the fracture-matrix interface assuming the conductive flux from rock matrix to fracture takes place transverse to the direction of the fracture.

In the present work, the one-dimensional equation representing the thermal transport in fracture has been adopted from Suresh Kumar \& Ghassemi (2005) with an improvement in order to consider the variatioin of fracture aperture. The modified equation is represented by Eq. 2 .

$$
\frac{\partial T_{f}}{\partial t}=-V(x) \frac{\partial T_{f}}{\partial x}+D_{f} \frac{\partial^{2} T_{f}}{\partial x^{2}}+D_{L}(x) \frac{\partial^{2} T_{f}}{\partial x^{2}}+\frac{\lambda_{m}(T)}{\rho_{w} C_{w} b(x)} \frac{\partial T_{m}}{\partial y} \mid y=b(x) .
$$

In Eq. (2), $T_{f}$ is relative temperature in fracture $(K) ; T_{m}$ is relative temperature in rock matrix $(K) ; t$ (day) is the time; $D_{f}\left(\mathrm{~m}^{2} /\right.$ day) is thermal conduction coefficient of fluid in fracture; $D_{L}(x)\left(\mathrm{m}^{2} /\right.$ day $)$ is longitudinal thermal dispersion coefficient; $V(x)(\mathrm{m} /$ day $)$ is the fluid velocity through fracture; $\lambda_{m}$ is thermal conductivity of reservoir matrix; $\rho_{w}\left(\mathrm{~kg} / \mathrm{m}^{3}\right)$ is density of fluid in fracture and $C_{w}(\mathrm{~J} / \mathrm{kgK})$ is specific heat capacity of fluid in fracture.

Thermal conduction coefficient of fluid in fracture $\left(D_{f}\right)$ is a function of fluid density $\left(\rho_{w}\right)$ and specific heat capacity of fluid in fracture $\left(C_{w}\right)$. The equation representing this relation is given by Eq. (3).

$$
D_{f}=\frac{\lambda_{f}}{\rho_{w} C_{w}}
$$

In Eq. (3), $\lambda_{f}(\mathrm{~W} / \mathrm{mK})$ is thermal conductivity of fluid in fracture.

The dispersion effect is due to parabolic velocity profile that causes the heat to distribute ahead and aft of the average fluid velocity. Longitudinal thermal dispersion coefficient (Cheng et al 2001) that characterizes the dispersion effect is given by Eq. (4).

$$
D_{L}(x)=\frac{V(x)[b(x)]^{2}}{210 D_{f}} .
$$

In Eq. (2), thermal convection is represented by first term on RHS, thermal conduction by the second and third terms and the fourth term represents the coupling between the fracture and rock matrix. Unlike the solute transport, the coupling in the thermal transport is not a function of porosity of rock matrix.

The equation representing the thermal transport in rock matrix adopted from Suresh Kumar \& Ghassemi (2005) is given by Eq. (5).

$$
\frac{\partial T_{m}}{\partial t}=\frac{\lambda_{m}(T)}{\rho_{m} C_{m}} \frac{\partial^{2} T_{m}}{\partial y^{2}} .
$$

In Eq. (5), $\lambda_{m}(T)$ is thermal conductivity of fluid in rock matrix as a function of temperature and $\rho_{m}(T)$ and $C_{m}(T)$ are rock density and rock specific heat, respectively as a function of temperature. 
Zoth \& Haenel (1988) gave a general empirical relation for thermal conductivity as a function of temperature (Eq. 6).

$$
\lambda_{m}(T)=\frac{A}{(350+T)}+N .
$$

In Equation (6), $A$ and $N$ are constants which are dependent on type of rock, $\lambda_{m}(T)$ is in W/mK and $T$ in ${ }^{\circ} \mathrm{C}$. For granite, quartz porphyry and granodiorite $A=807$ and $N=0.64$ (Vosteen \& Schellschmidt 2003).

The empirical relation (Somerton 1992) for $\rho_{m}(T)$ and $C_{m}(T)$ in the Eq. (5) is represented by Eqs. (7) and (8), respectively.

$$
\begin{gathered}
\rho_{m}(T)=\frac{2650}{[1+(T-20) \cdot 0.5 e-04]} \\
C_{m}(T)=1234.257-454.546 \cdot \exp (-.0039733482 \cdot T) .
\end{gathered}
$$

In Eqs. (7) and (8), $\rho_{m}(T)$ is in $K g / m^{3}$ and $C_{m}(T)$ in $J / k g K$ with $T$ in ${ }^{\circ} \mathrm{C}$. Equations (9)-(15) represent the initial and boundary conditions required to solve the governing Eqs. (2) and (5). At initial time (time, $t=0$ ) the temperature in both fracture and matrix is assumed to be a relative temperature of unity, while the fluid (water) is injected at a constant relative temperature of 0.5 at inlet (at $t>0)$.

Initial conditions

$$
\begin{gathered}
T_{f}(x, t=0)=1 \\
T_{m}(x, y, t=0)=1 .
\end{gathered}
$$

\section{Fracture inlet boundary condition in fracture}

In the present study, complex boundary conditions have been introduced at the fracture inlet (source). Two types of inlet (water injection temperature) boundary conditions have been used which are represented by Eqs. (11) and (12).

Case 1: Dirichlet type boundary condition (First Type)

$$
T_{f}(x=0, t)=0.5=T_{f o} .
$$

Case 2: Neumann type boundary condition (Second Type)

$$
\frac{\partial T_{f}(x=0, t)}{\partial x}=f(t) .
$$

The function $f(t)$ represents the 3 different rates of source temperature with respect to time.

$$
\begin{aligned}
& f(t)=T_{f o}(1-\sin (m t)) \quad \text { (Sinusoidally varying source) } \\
& f(t)=T_{f o} \exp (-m t) \quad(\text { Exponentially decreasing source) } \\
& f(t)=T_{f o} \quad \text { (Constant flux) } \\
& \frac{\partial T_{f}\left(x=L_{f}, t\right)}{\partial x}=0 \quad \text { (Right Fracture Boundary Condition) } \\
& T_{f}(x, t)=T_{m}(x=y=b(x), t) \text { (Interface Condition) } \\
& \frac{\partial T_{m}(x, y=B, t)}{\partial x}=0 \text { (Rock Matrix Boundary Condition). }
\end{aligned}
$$


Table 1. Maximum, minimum and average half fracture aperture values for each of the aperture profiles.

\begin{tabular}{lccc}
\hline Aperture variation profile & $\begin{array}{c}\text { Maximum half fracture } \\
\text { aperture }(\mu \mathrm{m})\end{array}$ & $\begin{array}{c}\text { Minimum half fracture } \\
\text { aperture }(\mu \mathrm{m})\end{array}$ & $\begin{array}{c}\text { Average half fracture } \\
\text { aperture }(\mu \mathrm{m})\end{array}$ \\
\hline Sinusoidal & 120 & 80 & 100 \\
Logarithmic & 143 & 67 & 97.5 \\
Parallel plate & 100 & 100 & 100 \\
\hline
\end{tabular}

To effectively incorporate the variation of fracture aperture in variable aperture model, two different functions have been used in the present study. One of the functions gives a sinusoidal variation to the fracture aperture as shown in figure 1, which is represented by Eq. (16). The other function gives a logarithmical variation to fracture with decaying aperture size from fracture inlet to outlet represented by Eq. (17).

$$
\begin{gathered}
b(x)=A m\left[1+\frac{d}{A m} \cdot \sin \left(\frac{n \pi x}{w}\right)\right] \\
b(x)=A m \cdot \exp (m x) \cdot(1+\sin (n \pi x))+a .
\end{gathered}
$$

In Eqs. (16) and (17), Am [L] and $w$ [L] are the maximum aperture width and distance between consecutive troughs/crests in meters and $m, n, a[\mathrm{~L}]$ and $d[\mathrm{~L}]$ are numerical constants which decide the nature of variation. For the effective comparative analysis between parallel plate and variable aperture model, the average value of the $b(x)$ along the fracture length is taken as the equivalent fracture aperture for the parallel plate model $\left(b(x)_{\text {avg }}=b\right)$ as shown in table 1 . It should also be noted from table 1 that even though there is large variation in maximum and minimum values of fracture aperture among the different profiles, the average value of fracture aperture along the fracture length is approximately around $100 \mu \mathrm{m}$.

Convection is the major phenomena in the propagation of thermal fronts through the fracture of a fracture-matrix system and is function of velocity of the fluid. Harr (1962) presented an expression for a single horizontal coupled fracture-matrix system, the fluid velocity trough a single fracture for a non-turbulent, viscous, incompressible flow neglecting inertia forces as a solution of Navier-Stokes equation given by Eq. (18) (Grisak \& Pickens 1980; Lipson et al 2005).

$$
V(x)=\frac{\rho_{w} g[b(x)]^{2}}{12 \mu} \nabla h .
$$

In Eq. (18), $\nabla h$ is the hydraulic gradient whose value ranges from 0.003 to 0.007 for fracture (Lipson et al 2005), $V(x)$ is the average velocity of the flow parallel to horizontal fracture, $\mu\left(\mathrm{N}-\mathrm{s} / \mathrm{m}^{2}\right)$ is the dynamic viscosity of the fluid, $\rho_{w}\left(\mathrm{~kg} / \mathrm{m}^{3}\right)$ and $g\left(\mathrm{~m} / \mathrm{s}^{2}\right)$ are density of the fluid through the fractured porous media and acceleration due to gravity, respectively. Here $x$ represents flow in horizontal direction (along the fracture).

\subsection{Effective heat transfer factor}

To effectively and easily understand the extent of heat transfer from rock matrix to fluid in fracture a new non-dimensional parameter called 'effective heat transfer factor' is introduced for the first time in the present study. Eq. (19) gives the mathematical expression for the factor.

$$
\varepsilon_{T}=\frac{L_{f}-L_{o}}{L_{f}} .
$$


In Eq. (19), $L_{f}$ is the length of the fracture (limited to $30 \mathrm{~m}$ in this study) and $L_{o}$ is the point at which the propagation reaches unit relative temperature in fracture (saturation point measured from fracture inlet) that is the point at which it attains the temperature of the rock matrix. Lesser the value of $L_{o}$, the closer will be the point of unit relative temperature to the fracture inlet. This indicates a greater heat exchange at fracture-matrix interface. Greater the value of $L_{o}$, further will be the point of unit relative temperature from fracture inlet, which indicates reduced heat exchange at fracture-matrix interface. The value of $\varepsilon_{T}$ ranges from 0 to 1 . For $\varepsilon_{T}=1.0, L_{o}$ will be zero, which signifies the conditions wherein the fluid attains the rock matrix temperature (relative temperature $=1.0$ ) instantaneously upon entering the fracture, a hypothetical scenario signifying an infinite conduction. Minimum heat transfer from hot rock matrix to fluid in fracture occurs when $L_{o}$ attains the value of $L_{f}$ effectively making $\varepsilon_{T}=0$. In this condition, either the fluid attains the rock matrix temperature near the exit of the fracture or exits the fracture at temperature lower than the rock matrix. Hence this non-dimensional parameter quantifies the extent of thermal front propagation in the fracture.

\section{Numerical model and verification}

A single fracture-matrix system considered in the present numerical study is described by a set of coupled partial differential equations, Eq. (2) represents thermal front within fracture, while Eq. (5) within porous rock matrix. These set of equations are solved using a fully implicit finite difference method. Iteration is performed at each time step to satisfy the continuity at the fracture-matrix interface. A uniform grid spacing is adopted along fracture and a geometrically varying (increasing) grid spacing is used along the rock matrix perpendicular to flow in fracture. The grid size in rock matrix increases geometrically with the size of first grid is equal to half of the fracture aperture at that point.

In the present study, the rock thermal conductivity of $\left(\lambda_{\mathrm{m}}\right)$ is as a function of temperature (Eq. (6)) and is calculated at each grid point at every time step. The value of rock thermal conductivity $\left(\lambda_{\mathrm{m}}\right)$ is taken as input into coefficient of conduction term (Eq. (5)). Hence both spatial and temporal variation of rock thermal conductivity $\left(\lambda_{\mathrm{m}}\right)$ and coefficient of the conduction term in Eq. (5) with respect to temperature has been captured for unsteady analysis.

A first order implicit forward difference is used to discretize the convective term (first term on RHS of Eq. (2)), second order implicit central difference is used to discretize the conduction terms (second term and third on RHS of Eq. (2)), a two point backward finite difference is used to discretize the temporal term (term on LHS of Eq. (2)) and an implicit first order forward difference is used to discretize the coupling term (fourth term on the RHS of Eq. (2)). Second order implicit central difference is used to discretize the conduction term in Eq. (5).

Figure 2 shows the comparison of the present numerical model for parallel fracture aperture with that of available analytical solution given by Sudicky \& Frind (1982). The respective fracture and matrix parameters used for the comparison have been tabulated in table 2 . It is seen from figure 2 that the present numerical model is in close agreement with the model presented by Sudicky \& Frind (1982).

\section{Results and discussions}

A numerical model has been developed to analyse the propagation of thermal front in a single horizontal coupled fracture-matrix system with variable fracture aperture using a fully implicit 


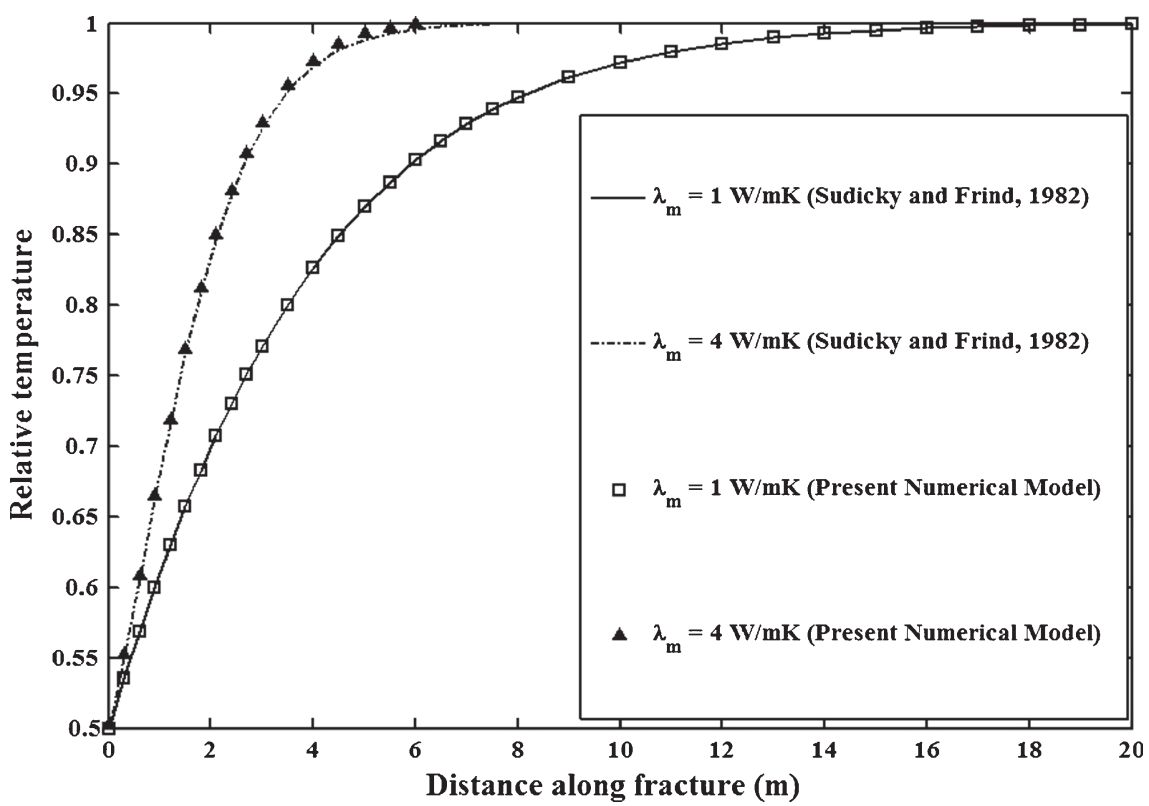

Figure 2. Verification of the present numerical model with parallel fracture aperture with that of available analytical solution given by Sudicky \& Frind (1982).

finite difference model. Sensitivity analysis of rock thermal conductivity and fracture aperture has been performed. Further, dependence of propagation of thermal fronts on inlet (water injection temperature) boundary condition has been studied. The parameters used for the analysis are tabulated in table 2.

Table 2. Transport parameters used for verification of the present numerical model for parallel plate model.

\begin{tabular}{ll}
\hline Parameters & Values \\
\hline Grid spacing in fracture, $\Delta x(\mathrm{~m})$ & 0.005 \\
Time step, $\Delta t$ (days) & 0.005 \\
Simulation time (days), $T_{s}$ & 100 \\
Thermal conduction coefficient of fluid in fracture, $D_{f}\left(\mathrm{~m}^{2} /\right.$ day $)$ & Equation 3 \\
Longitudinal thermal dispersion coefficient in fracture, $D_{L}\left(\mathrm{~m}^{2} /\right.$ day $)$ & Equation 4 \\
Density of fluid, $\rho_{w}\left(\mathrm{~kg} / \mathrm{m}^{3}\right)$ & 1000 \\
Density of rock matrix, $\rho_{m}\left(\mathrm{~kg} / \mathrm{m}^{3}\right)$ & Equation 7 \\
Rock thermal conductivity, $\lambda_{m}(\mathrm{~W} / \mathrm{mK})$ & Equation 6 \\
Thermal conductivity of fluid in fracture, $\lambda_{f}(\mathrm{~W} / \mathrm{mK})$ & 0.5 \\
Specific heat of water, $C_{w}(\mathrm{~J} / \mathrm{kg} \mathrm{K})$ & 5000 \\
Specific heat of rock matrix, $C_{m}(\mathrm{~J} / \mathrm{kg} \mathrm{K})$ & Equation 8 \\
Half fracture aperture, $b(\mu \mathrm{m})$ & $75-300$ \\
Velocity of fluid, $V(x)(\mathrm{m} / \mathrm{day})$ & Equation 18 \\
Length of fracture, $L_{f}(\mathrm{~m})$ & 30 \\
Half fracture spacing, $B(\mathrm{~m})$ & 0.15 \\
\hline
\end{tabular}


Figure 3 shows the spatial propagation of thermal fronts in fracture for a single fracturematrix system for both parallel plate model and variable aperture model for different averaged fracture apertures $(\mathrm{b}=75-300 \mu \mathrm{m})$. The ordinate of the plot represents the relative temperature in fracture and abscissa represents the distance along the fracture $(\mathrm{m})$. It is observed from figure 3 that for both parallel and variable aperture models, the point at which the fluid temperature in fracture approaches the relative temperature of unity tends to move further away from fracture with the increase in half fracture aperture. Thus, there is a reduction in heat transfer from at the fracture-matrix interface. There is an increase in the fluid velocity with the increase in average half fracture aperture, which varies as a square of fracture aperture (Eq. 18). The increase in the fluid velocity with aperture leads to a greater convective heat transport along the fracture. Further, the coupling between the rock matrix and the fracture gets weakened with increase in fracture aperture since it varies inversely with the aperture (fourth term in RHS of Eq. (2)). The combined effect of these two phenomena, shifts the point at which the fluid temperature in fracture approaches the relative temperature of unit further away from fracture with the increase in half fracture aperture. However, compared to the parallel plate model the position of unit relative temperature of thermal front is nearer to fracture aperture for the variable aperture model. It can be observed from figure 3 that there is a negligible difference between the two models for smaller fracture aperture $(b=75 \mu \mathrm{m})$. As the fracture aperture increases $(\mathrm{b}=150 \mu \mathrm{m})$, the distance of unit relative temperature point from fracture inlet $\left(L_{o}\right)$ also increases and $L_{o}$ becomes significantly large at $\mathrm{b}=300 \mu \mathrm{m}$. Further it can be observed that at $\mathrm{b}=75 \mu \mathrm{m}$ the relative temperature profile is hyperbolic in nature (indicating a relatively greater heat transfer from rock matrix to fracture) for both parallel and variable aperture (sinusoidal and logarithmic) model. At higher average half fracture aperture $(b=150 \mu \mathrm{m})$ the relative temperature profile for variable aperture model is still hyperbolic in nature, however the temperature profile for the parallel plate model is more of parabolic in nature, indicating lesser heat transfer rate from rock matrix to fracture. At high values of average half fracture aperture $(b=300 \mu \mathrm{m})$ the temperature profile is parabolic in nature for variable aperture model and almost linear for the parallel plate model. Thus the presence of variable aperture alters the rate of thermal transport between fracture and rock matrix. This deviation in the point at which the fluid attains the temperature of rock

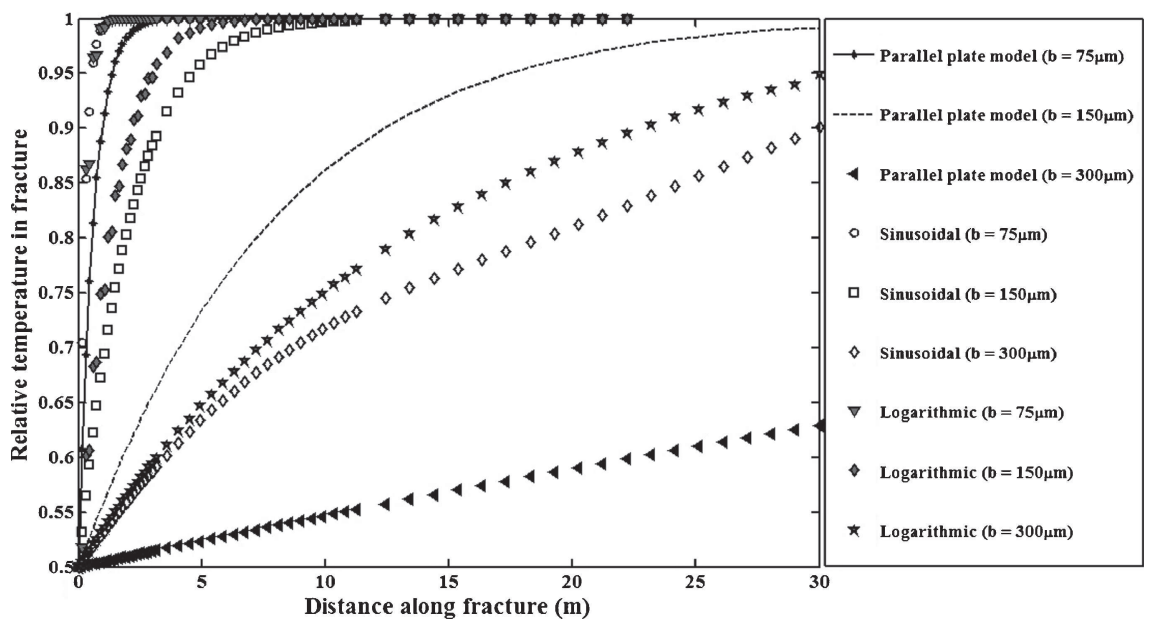

Figure 3. Spatial propagation of thermal fronts in fracture for a single fracture-matrix system, considering both parallel plate model and variable aperture model for different fracture aperture $(b=75-300 \mu \mathrm{m})$. 
matrix occurs is due to the curvature or undulated surface of fracture wall which increases the surface area. The increased surface area in variable aperture model causes greater heat transfer at fracture-matrix interface and hence the fluid attains unit relative temperature sooner than for parallel plate model.

Figure 4 shows the spatial variation of the thermal front propagation for parallel plate and variable aperture model in rock matrix at a cross section $1.5 \mathrm{~m}$ from fracture inlet (point of water injection). The ordinate of the plot represents the relative temperature in rock matrix and abscissa represents the distance along the rock matrix $(\mathrm{m})$. The analysis is carried out for different values of half fracture apertures $(b=75-300 \mu \mathrm{m})$. It is observed from figure 4a that for half fracture of $\mathrm{b}=75 \mu \mathrm{m}$, there is a significant difference in thermal front along the rock matrix for variable aperture model compared to the parallel palate model. However, this difference decreases as half fracture aperture increases to $150 \mu \mathrm{m}$ (figure 4b) and finally the difference is negligible (profiles overlap) at $300 \mu \mathrm{m}$ (figure $4 \mathrm{c}$ ). Further at $\mathrm{b}=75 \mu \mathrm{m}$ the temperature profile for variable aperture model (sinusoidal and logarithmic) has a parabolic nature indicating a higher heat transfer (parabolic heat Eq. (5)), the same cannot be said about parallel plate model as the temperature profile is less parabolic in nature as compared to variable aperture model. However, as half fracture aperture increases the temperature profile for both parallel plate and variable aperture

(a)

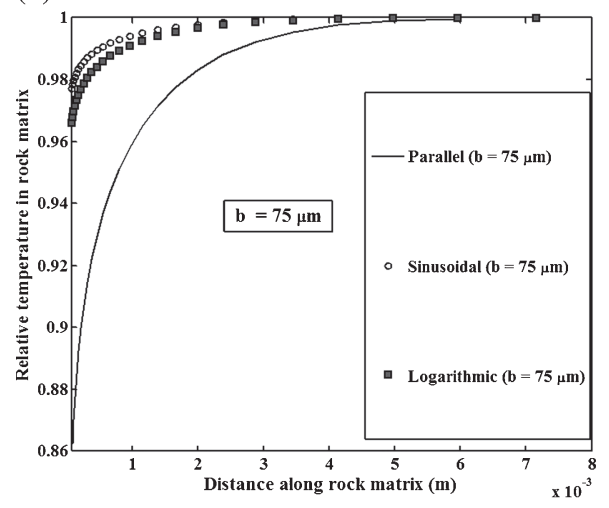

(b)

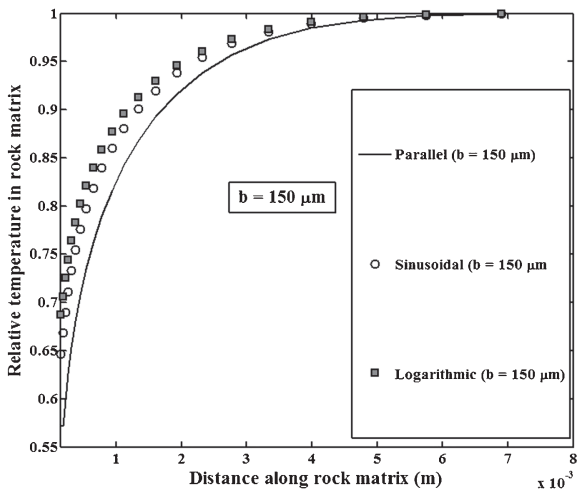

(c)

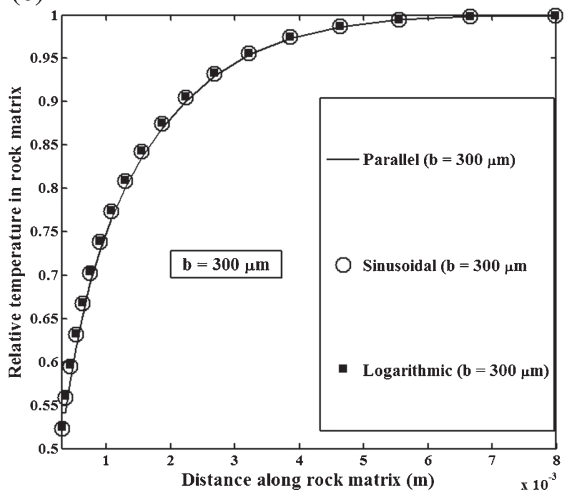

Figure 4. Spatial variation of the thermal front propagation for both parallel plate and variable aperture model in rock matrix at a cross section $1.5 \mathrm{~m}$ from fracture inlet (point of water injection). 
behaves in similar manner (less parabolic). Thus the thermal fronts in the rock matrix depends significantly on type of model used at lower fractures apertures. This difference between the behaviour of the variable aperture and parallel plate model gets reduced as the fracture aperture increases, becoming insignificant beyond $300 \mu \mathrm{m}$.

Table 3 shows the values of thermal saturation point $\left(L_{o}\right)$ and effective heat transfer factor $\left(\varepsilon_{T}\right)$ at different values of half fracture aperture $(\mathrm{b}=50,100$ and $150 \mu \mathrm{m})$ for both parallel plate and variable aperture model (sinusoidal and logarithmic). It is observed from table 3 that for low half fracture aperture value $(\mathrm{b}=50 \mu \mathrm{m})$ the thermal saturation point $\left(L_{o}\right)$ (unit relative temperature of fluid in fracture) for parallel, sinusoidal and logarithmic aperture variations have small values of $L_{o}$, signifying their nearness to fracture inlet. The effective heat transfer factor $\left(\varepsilon_{T}\right)$ is very close to unit for all the fracture variation types for $\mathrm{b}=50 \mu \mathrm{m}$. This indicates a greater heat transfer from rock matrix to fracture for the small fracture aperture values for all fracture variation types. From table 3 at the half fracture aperture of $b=100 \mu \mathrm{m}$, the value of $L_{o}$ increases indicating the shift of saturation point away from fracture inlet for all the types of fracture variations. However, this shift is greater for the parallel plate model as compared to logarithmic and sinusoidal aperture variations. With the increase in value of $L_{o}$, the magnitude of numerator in Eq. (19) becomes smaller and value of effective heat transfer factor $\left(\varepsilon_{T}\right)$ decreases. There is a greater reduction of $\varepsilon_{T}$ for the parallel plate model compared to variable aperture model (sinusoidal and logarithmic), indicating a lesser heat exchange for parallel plate model as compared to variable aperture model. At half fracture aperture of $150 \mu \mathrm{m}$, the $\varepsilon_{T}$ is almost negligible for parallel plate model as $L_{o}(28.305 \mathrm{~m})$ is very close to $L_{f}(30 \mathrm{~m})$ making the numerator in Eq. (19) very small and hence a very low heat transfer from rock to fluid in fracture. However, for variable aperture model $\varepsilon_{T}$ still has considerable values as compared to parallel plate model indicating moderate heat transfer even at large values of half fracture aperture. The curvature introduced to the fracture aperture in variable aperture model increases the surface area for the extra heat transfer and even the velocity is varied in variable aperture model which effects the convection process.

Figure 5 shows the spatial variation of the rock thermal conductivity $\left(\lambda_{m}\right)$ and thermal conduction coefficient of fluid in fracture (coefficient of the conduction term in Eq. (5)) along rock matrix at a cross-section located at $1.5 \mathrm{~m}$ from fracture inlet. In figures $5 \mathrm{a}$ and $\mathrm{b}$ rock thermal conductivity $\left(\lambda_{m}\right)$ and thermal conduction coefficient of rock are represented on the ordinate and distance along the rock matrix $(\mathrm{m})$ (along $\mathrm{x}$ axis) on abscissa. The analysis is done for both parallel plate and variable aperture model for half fracture aperture of $b=100 \mu \mathrm{m}$ (rest of the data remains unchanged in table 2 ). It is observed from figures $5 \mathrm{a}$ and $\mathrm{b}$ that rock thermal conductivity $\left(\lambda_{\mathrm{m}}\right)$ and thermal conduction coefficient of rock will have a larger variation for parallel plate model due to a slower heat transfer rate as compared to variable aperture model. This is due to the presence of curvature in variable aperture model, which has increased heat transfer rate. In the present study, thermal conductivity of rock $\left(\lambda_{\mathrm{m}}\right)$ and thermal conduction coefficient of rock are taken as function of temperature (Eqs. (6) and (3)), respectively.

Table 3. $L_{o}$ and $\varepsilon_{T}$ values for different fracture aperture widths.

\begin{tabular}{|c|c|c|c|c|c|c|}
\hline \multirow[b]{2}{*}{ Fracture variation } & \multicolumn{2}{|c|}{$\mathrm{b}=50 \mu \mathrm{m}$} & \multicolumn{2}{|c|}{$\mathrm{b}=100 \mu \mathrm{m}$} & \multicolumn{2}{|c|}{$\mathrm{b}=150 \mu \mathrm{m}$} \\
\hline & $\begin{array}{c}\text { Effective heat } \\
\text { transfer factor: } \varepsilon_{T}\end{array}$ & $\begin{array}{c}\text { Thermal saturation } \\
\text { point: } L_{o}(\mathrm{~m})\end{array}$ & $\begin{array}{c}\text { Effective heat } \\
\text { transfer factor: } \varepsilon_{T}\end{array}$ & $\begin{array}{c}\text { Thermal saturation } \\
\text { point: } L_{o}(\mathrm{~m})\end{array}$ & $\begin{array}{c}\text { Effective heat } \\
\text { transfer factor: } \varepsilon_{T}\end{array}$ & $\begin{array}{c}\text { Thermal saturation } \\
\text { point: } L_{o}(\mathrm{~m})\end{array}$ \\
\hline Parallel plate model & 0.982500 & 0.525000 & 0.784000 & 6.480000 & 0.056500 & 28.305000 \\
\hline Sinusoidal & 0.991500 & 0.255000 & 0.89750 & 3.075000 & 0.760500 & 7.185000 \\
\hline Logarithmic & 0.990500 & 0.285000 & 0.921000 & 2.370000 & 0.65750 & 10.275000 \\
\hline
\end{tabular}




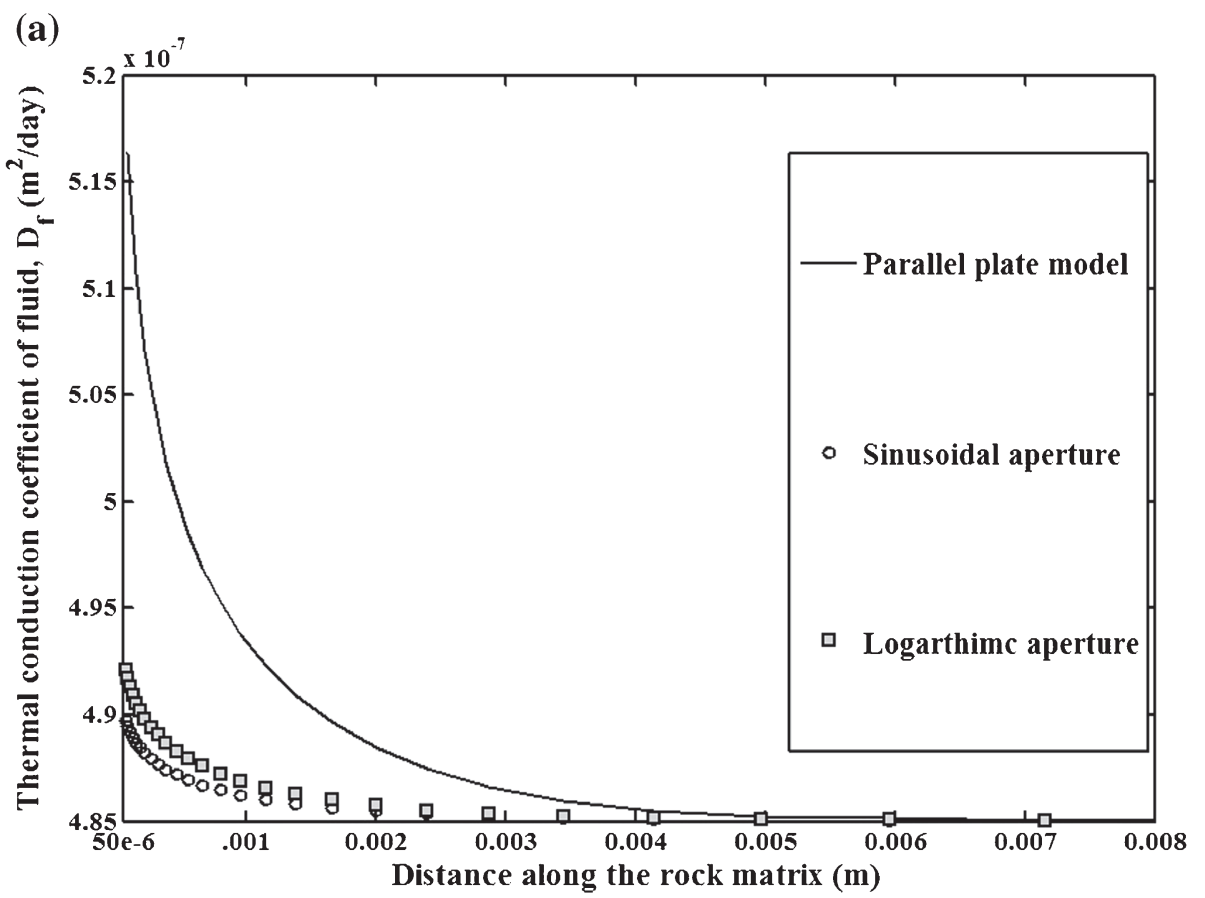

(b)

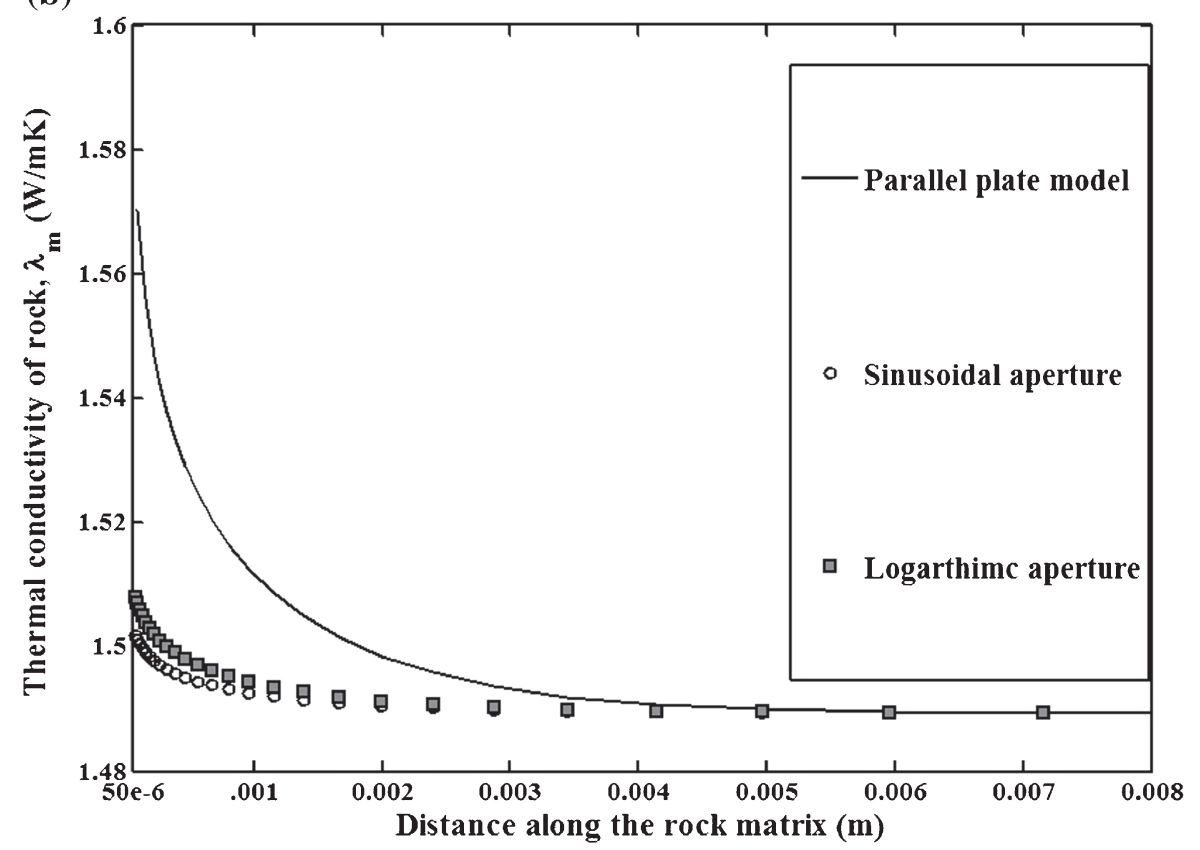

Figure 5. Spatial variation of the thermal conductivity of rock $\left(\lambda_{\mathrm{m}}\right)$ and thermal conduction coefficient of fracture along rock matrix at a cross-section located at $1.5 \mathrm{~m}$ from fracture inlet for $\mathrm{b}=100 \mu \mathrm{m}$. 
Figure 6 shows the spatial variation of thermal front propagation in fracture for different values of rock thermal conductivity $\left(\lambda_{\mathrm{m}}\right)$ for a half fracture aperture of $\mathrm{b}=75 \mu \mathrm{m}$. It is observed from figure 6 that both parallel plate and variable aperture model, the thermal front in fracture is sensitive to variations in rock thermal conductivity $\left(\lambda_{\mathrm{m}}\right)$. However, the sensitivity is more in the case of parallel plate model as compared to variable aperture model. This tells that the heat transfer from rock matrix to fracture for the case of parallel plate is heavily dependent on the rock thermal conductivity $\left(\lambda_{\mathrm{m}}\right)$. Hence considerable thermal front variation is observed in figure 6 with variation in $\lambda_{\mathrm{m}}$. However, for the case of variable fracture aperture the heat transfer not only dependent on the $\lambda_{\mathrm{m}}$ but also on the increased curvature of the fracture wall. Hence there is no considerable change observed in thermal front propagation for the case of variable fracture aperture for different values of rock thermal conductivity $\left(\lambda_{\mathrm{m}}\right)$.

Figure 7 shows the effect of various types of boundary condition (Dirichelt, Neuman - Exponential Type Source, Neuman - Pulse Type Source, Neuman - Constant Flux Type Source) on the thermal front propagation in fracture at a fixed average fracture aperture of $\mathrm{b}=75 \mu \mathrm{m}$. Figure $7 \mathrm{a}$ represents the effect of different types of boundary conditions on spatial variation of thermal front for the case of the parallel plate model. Figure $7 \mathrm{~b}$ represents the effect of different types of boundary conditions on spatial variation of thermal front for the case of variable aperture model. As observed from figures $7 \mathrm{a}$ and $\mathrm{b}$, unlike what has been observed in solute/colloidal transport (Batu \& Genuchten 1990; Logan et al 1996; Allaire et al 2002), the sensitivity of boundary conditions (injection condition) on the propagation of thermal fronts in a coupled fracture-matrix system nearly remains insignificant. A very negligible change in spatial variation of thermal front propagation along fracture can be observed in the vicinity of fracture inlet, while the location, where it reaches unit relative temperature remain the same, irrespective of the boundary conditions. This trend is observed for both variable aperture (figure $7 b$ ) and the parallel plate model (figure 7a).

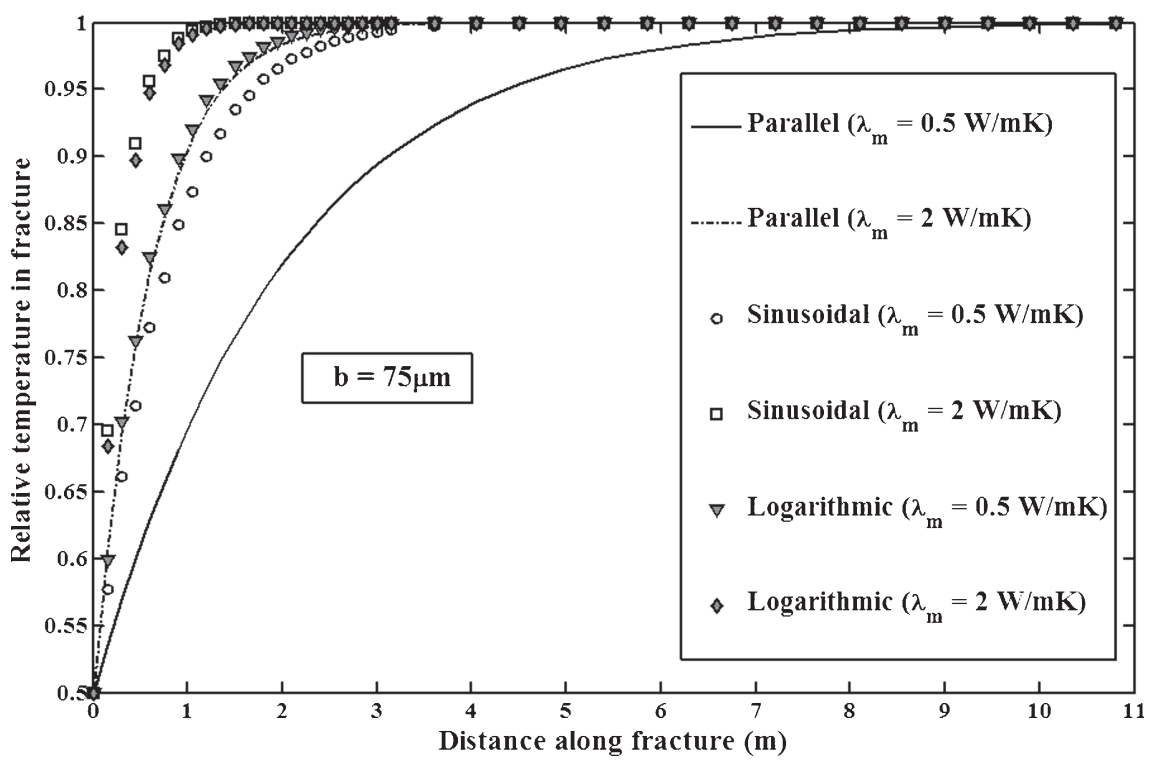

Figure 6. Spatial variation of thermal front propagation in fracture for different values of rock thermal conductivity $\left(\lambda_{m}\right)$ for a half fracture aperture of $\mathrm{b}=75 \mu \mathrm{m}$. 
(a)

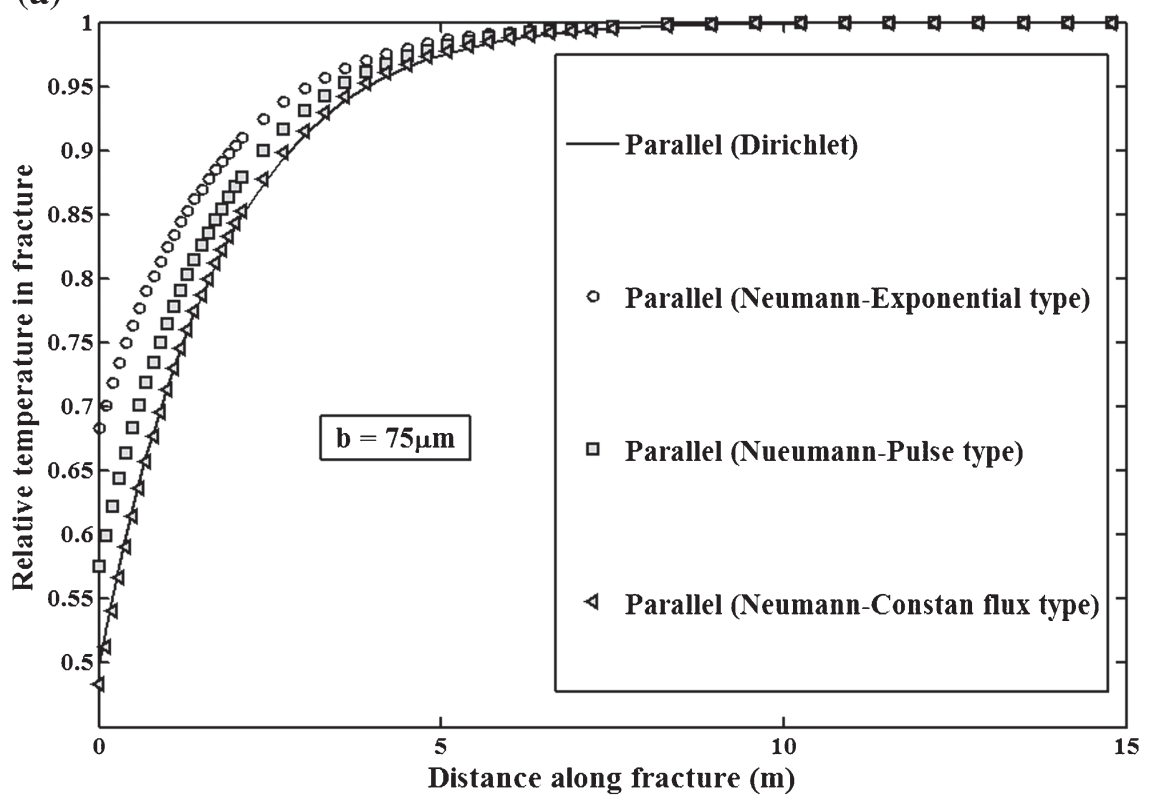

(b)

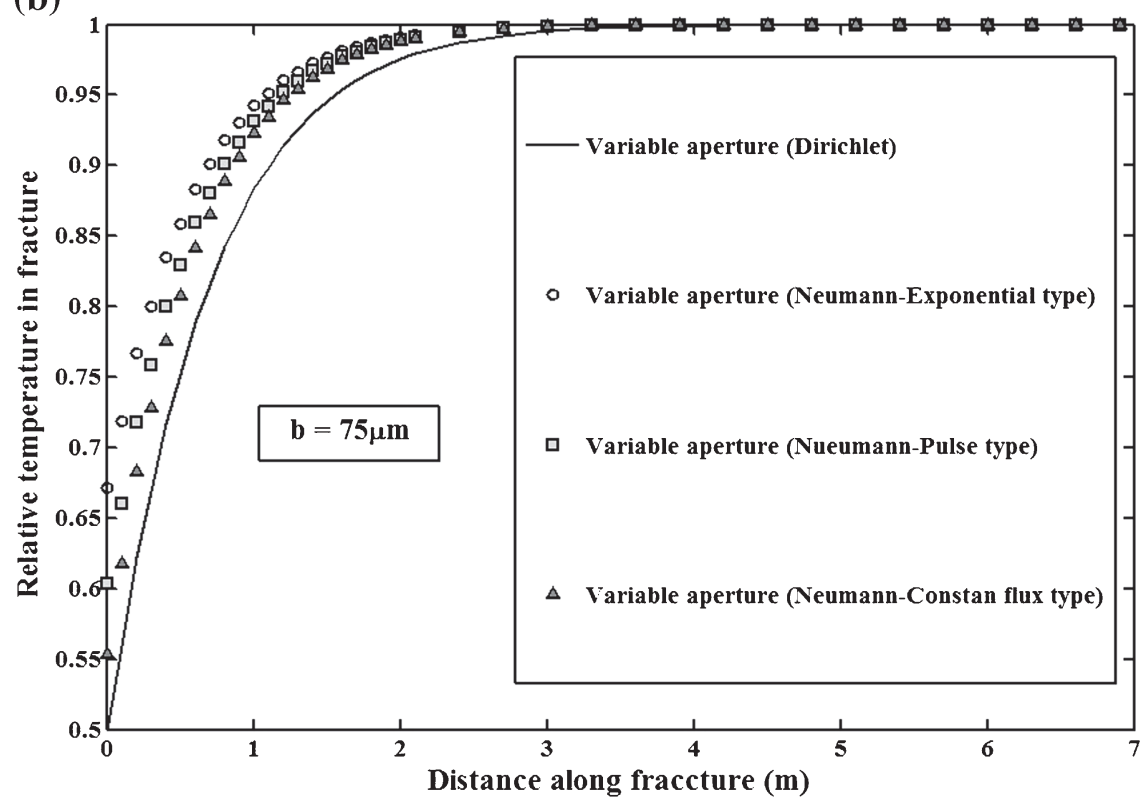

Figure 7. Effect of various types of boundary conditions on the thermal front propagation in fracture for fracture-matrix system at a fracture aperture of $\mathrm{b}=75 \mu \mathrm{m}$.

\section{Conclusions}

An implicit finite difference scheme has been used to investigate the propagation of thermal front in single fracture-matrix system. Effect of variation of fracture aperture on the thermal 
front has been analysed by implementing sinusoidally and logarithmically varying fracture aperture in the present study. Rock thermal conductivity and the coefficient of thermal conduction are considered as a function of temperature. Effect of the boundary condition on the thermal propagation is also studied. Further, sensitivity analysis of thermal conductivity of rock and half fracture aperture have been analysed. The following conclusions were made from the combined analysis.

(i) The numerical results suggest that conventional parallel plate model significantly underestimates the thermal front propagation along the fracture, while the proposed variable fracture apertures using sinusoidal and logarithmic variations have a significantly different thermal front as compared to the conventional parallel plate model.

(ii) There is greater amount of heat transfer at fracture-matrix interface for variable aperture model as compared to parallel plate model due to increased curvature (undulated surface).

(iii) The thermal front propagation is sensitive to changes in fracture aperture. At small averaged fracture aperture the heat transfer at fracture-matrix interface is very high (particularly for variable aperture model) and the heat transfer decreases with the increase in fracture aperture. This effect is more prominent for the case of the parallel plate model as compared to variable aperture model, due to absence of any undulation in fracture aperture. At large fracture apertures, both parallel plate and variable aperture model yield the same heat transfer rate at fracture-matrix interface.

(iv) The heat transfer at the fracture-matrix interface for the case of parallel plate model is greatly dependent on the rock thermal conductivity $(\lambda \mathrm{m})$ as compared to variable aperture model, while the heat transfer rate at fracture-matrix interface for variable aperture model is dependent on both variation (increased surface area) of fracture aperture and rock thermal conductivity $(\lambda \mathrm{m})$, adding to an increased heat transfer.

(v) Unlike solute/colloidal transport in fracture-matrix system, different types of boundary conditions (injection condition) has negligible effect on the heat transfer at fracture-matrix interface for all the aperture models.

\section{References}

Allaire S E, Gupta S C, Nieber J and Moncrief J F 2002 Role of macropore continuity and tortuosity on solute transport in soils: 1. Effects of initial and boundary conditions. J. Contaminant Hydrol. 58(3): 299-321

Batu V and Genuchten M T 1990 First-and third-type boundary conditions in two-dimensional solute transport modeling. Water Resources Research 26(2): 339-350

Cheng AH-D, Ghassemi A and Detournay E 2001 Integral equation solution of heat extraction from a fracture in hot dry rock. Int. J. Numerical and Analytical Methods in Geomech. 25(13): 1327-1338

Feder J 1988 Fractals, New York:Plenum 283 pp

Gringarten A C and Sauty J P 1975 A theoretical study of heat extraction from aquifers with uniform regional flow. J. Geophys. Res. 80(35): 4956-4962

Gringarten A C, Witherspoon P A and Yuzo Ohnishi 1975 Theory of heat extraction from fractured hot dry rock. J. Geophys. Res. 80(8): 1120-1124

Grisak G E and Pickens J F 1980 Solute transport through fractured media: 1. The effect of matrix diffusion. Water Resources Research 16(4): 719-730

Hakami E and Barton N 1990 Aperture measurements and flow experiments using transparent replicas of rock joints. Proceedings of the Int, Symposium on Rock joints, edited by N. Barton and O. Stephsson, Balkema, Rotterdam Netherlands, pp. 383-390

Harr M E 1962 Groundwater and seepage. New York: McGraw-Hill 315 pp 
Heuer N, Küpper T and Windelberg D 1991 Mathematical model of a Hot Dry Rock system. Geophys. J. Int. 105: 659-664 DOI: 10.1111/j.1365-246X.1991.tb00803.x

Keller K and Bonner B P 1985 Automatic, digital system for profiling rough surfaces. Review of scientific instruments 56(2): 330-331

Kolditz Olaf and Christoph Clauser 1998 Numerical simulation of flow and heat transfer in fractured crystalline rocks: Application to the hot dry rock site in Rosemanowes (UK). Geothermics 27(1): 1-23

Lauwerier H A 1955 The transport of heat in an oil layer caused by the injection of hot fluid. Appl. Scientific Research Section A 5(2-3): 145-150

Lipson D S, Kueper B H and Gefell M J 2005 Matrix Diffusion-Derived Plume Attenuation in Fractured Bedrock. Groundwater 43(1): 30-39

Liu E 2005 Effects of fracture aperture and roughness on hydraulic and mechanical properties of rocks: implication of seismic characterization of fractured reservoirs. J. Geophys. Eng. 2(1): 38

Liu Q Q and Fan H G 2011 An Approach to Estimate the Flow Through an Irregular Fracture. In recent progresses in fluid dynamics research: Proceeding of the Sixth International Conference on Fluid Mechanics, AIP Publishing, 1376(1):382-385

Logan J D, Zlotnik V A and Cohn S 1996 Transport in fractured porous media with time-periodic boundary conditions. Mathematical and Computer Modelling 24(9): 1-9

Natarajan N and Suresh Kumar G 2010 Solute transport in a coupled fracture-matrix system with sinusoidal fracture geometry. Int. J. Eng. Sci. Technol. 2(6): 1886-1892

Natarajan N and Suresh Kumar G 2011a Numerical modeling and spatial moment analysis of thermal fronts in a coupled fracture-skin-matrix system. Geotechnical and Geological Eng. 29(4): 477-491

Natarajan N and Suresh Kumar G 2011b Spatial moment analysis of colloid facilitated radionuclide transport in a coupled fracture-matrix system. Int. J. Energy \& Environment 2(3): 491-504

Renu V and Suresh Kumar G 2012 Numerical Modeling and Spatial Moment Analysis of Solute Mobility and Spreading in a Coupled Fracture-Skin-Matrix System. Geotechnical and Geological Eng. 30(6): 1289-1302

Schulz R 1987 Analytical model-calculations for heat-exchange in a confined aquifer. J. Geophysicszeitschrift fur Geophysik 61(1): 12-20

Shook Michael G 2001 Predicting thermal breakthrough in heterogeneous media from tracer tests. Geothermics 30(6): 573-589

Somerton W H 1992 Thermal properties and temperature-related behavior of rock/fluid systems. (Vol. 37). Elsevier

Sudicky E A and Frind E O 1982 Contaminant transport in fractured porous media: Analytical solutions for a system of parallel fractures. Water Resour. Res. 18, 6 : 1634-1642 DOI: 10.1029/WR018i006p01634

Suresh Kumar G and Ghassemi A 2005 Numerical modeling of non-isothermal quartz dissolution/precipitation in a coupled fracture-matrix system. Geothermics 34(4): 411-439

Suresh Kumar G and Sekhar M 2005 Spatial moment analysis for transport of non-reactive solutes in a fracture matrix system. J. Hydrol. Eng. 10(3): 192-199

Suresh Kumar G and Ghassemi A 2006 Spatial Moment Analysis for One-Dimensional Non-Isothermal Quartz Transport and Dissolution/Precipitation in Fracture-Matrix System. J. Hydrol. Eng. 11(4): 338346

Suresh Kumar G 2008 Effect of sorption intensities on dispersivity and macro-dispersion coefficient in a single fracture with matrix diffusion. Hydrogeol. J. 16(2): 235-249

Suresh Kumar G 2009 Influence of Sorption Intensity on Solute Mobility in a Fractured Formation. $J$. Environmental Eng. 135(1): 1-7

Suresh Kumar G 2014 Mathematical Modeling of Groundwater Flow and Solute Transport in a Saturated Fractured Rock using Dual-Porosity Approach. J. Hydrol. Eng. 10: 1061 DOI: 1943-5584.0000986

Vosteen H D and Schellschmidt R 2003 Influence of temperature on thermal conductivity, thermal capacity and thermal diffusivity for different types of rock. Physics and Chemistry of the Earth Parts $A / B / C 28(9)$ : 499-509

Witherspoon P A, Wang J S Y, Iwai K and Gale J E 1980 Validity of cubic law for fluid flow in deformable rock fracture. Water Resources Res. 16(6): 1016-1024 
Zimmerman R W and Bodvarsson G S 1996 Hydraulic conductivity of rock fractures. Transport in porous media 23(1): 1-30

Zoth G and Haenel R 1988 Appendix. Handbook of terrestrial heat-flow density determination. Netherlands: Springer pp 449-468 